\title{
Millimeter-Wave Communications
}

\author{
Manuel García Sánchez \\ atlanTTic Research Center, Signal Theory and Communications Department, University of Vigo, 36310 Vigo, \\ Spain; manuel.garciasanchez@uvigo.es
}

Received: 24 January 2020; Accepted: 29 January 2020; Published: 3 February 2020

\section{Introduction}

For the last few decades, the millimeter wave (mmWave) frequency band (30-300 GHz) has been seen as a serious candidate to host very high data rate communications. First used for high capacity radio links, then for broadband indoor wireless networks, the interest in this frequency band has boosted, as it is proposed to accommodate future 5G mobile communication systems. The large bandwidth available in this frequency band will enable a number of new use cases for 5G. In addition, due to the large propagation attenuation, this frequency band may present some additional advantages regarding frequency reuse and communication security. On the other hand, however, a number of issues have to be addressed to make 5G mmWave communications viable: radio channel measurement, modeling, and estimation; antenna design and antenna measurement; beamforming and energy efficiency; commercial hardware design and development; multiple-input multiple-output (MIMO) and massive MIMO (m-MIMO) techniques; multi-cell cooperation; network planning and interference; system performance assessment and optimization; and finally, the study of new case uses and applications.

\section{Contributions in This Special Issue}

Each of the twelve papers collected in this Special Issue contributes to a solution to one or more of the challenges described in the introduction. Regarding radio wave propagation, Rubio et al. [1] provide an experimental characterization of the path loss and time-dispersion of an in office radio channel at $26 \mathrm{GHz}$, while in a study by Riobó and colleagues [2], wideband results at $40 \mathrm{GHz}$ and $60 \mathrm{GHz}$ frequency bands are also provided for indoor environments.

Two other papers [3,4] deal with the design and assessment of different kinds of antennas manufactured using three-dimensional (3D) printing. In one case, a $60 \mathrm{GHz}$ segmented parabolic reflective curved antenna, with a gain of $20 \mathrm{dBi}$ at $64 \mathrm{GHz}$, is presented by Cai, Sun, and Lei [3], while Massaccesi, Dassano, and Pirinoli [4] design a perforated dielectric transmitarray and analyze its beam scanning capabilities. Also related to beam steering antennas, Salem Hesari and Bornemann [5] describe the design, fabrication, and assessment of a substrate integrated waveguide variable phase shifter that may steer the radiation pattern of the antenna by $\pm 25^{\circ}$.

Another challenge for mmWave communication system is the design of amplifiers. Two different kinds of mmWave amplifiers are presented in two contributions. The design of a high-efficiency K-band MMIC linear amplifier using diode compensation is presented by Zhu and co-workers [6] together with its measured performance, while in a study by Doo and colleagues [7] a broadband mmWave waveguide package, which covers the entire W-band $(75-110 \mathrm{GHz})$, is presented and applied to build a low noise amplifier module. This module measures gains greater than $14.9 \mathrm{~dB}$ from $75 \mathrm{GHz}$ to $105 \mathrm{GHz}$ (12.9 dB at the entire $\mathrm{W}$-band) and noise figures less than $4.4 \mathrm{~dB}$ from $93.5 \mathrm{GHz}$ to $94.5 \mathrm{GHz}$.

For a proper design of the electronic systems at mmWave frequencies a good empirical characterization of the dielectric properties of the substrate material is of capital importance. In a 
study by Yang et al. [8] a description of the dielectric measurement of undoped silicon in the E-band (60-90 GHz) using a free-space quasi-optical system is provided.

Precoding is other key technology that will enable 5G mmWave communications. Castanheira and co-workers [9] present a sub-connected hybrid analog/digital multi-user linear equalizer combined with an analog precoder to efficiently remove the multi-user interference.

As propagation environment imposes several restrictions to radio wave propagation at mmWave frequencies and strong link blockage may occur, any technique to facilitate link recovery constitutes a significant contribution. A multibeam technique to speed up link recovery is presented by Aldalbahi [10]. Hriba and Valenti [11] discuss another way to mitigate link blocking by using macrodiversity techniques, however the performance of macrodiversity can be reduced if correlated blocking occurs in links to different base stations.

Finally, Duarte and colleagues [12] present a complete end-to-end 5G mmWave testbed fully reconfigurable based on a FPGA architecture.

\section{Future Trends}

The development of millimeter-wave communication systems has just started. Despite the recent developments to cope with the multiple challenges that researchers should solve, there is still a lot of work to be done. During the next years, we hope to assist in the exponential growth of contributions to this field: mm-Wave communications will lead us to full development of 5G case studies and beyond.

Acknowledgments: I would like to thank, in the first place, all the authors who decided to send they research contributions to this Special Issue. I also would like to thank all the reviewers for their comments that helped to improve the papers in this issue. Finally, I would like to thank MDPI editorial board and staff for the opportunity to guest-edit this Special Issue.

Conflicts of Interest: The author declares no conflicts of interest.

\section{References}

1. Rubio, L.; Torres, R.; Rodrigo Peñarrocha, V.; Pérez, J.; Fernández, H.; Molina-Garcia-Pardo, J.M.; Reig, J. Contribution to the Channel Path Loss and Time-Dispersion Characterization in an Office Environment at $26 \mathrm{GHz}$. Electronics 2019, 8, 1261. [CrossRef]

2. Riobó, M.; Hofman, R.; Cuiñas, I.; García Sánchez, M.; Verhaevert, J. Wideband Performance Comparison between the $40 \mathrm{GHz}$ and $60 \mathrm{GHz}$ Frequency Bands for Indoor Radio Channels. Electronics 2019, 8, 1234. [CrossRef]

3. Cai, B.; Sun, L.; Lei, Y. 3D Printing Using a 60 GHz Millimeter Wave Segmented Parabolic Reflective Curved Antenna. Electronics 2019, 8, 203. [CrossRef]

4. Massaccesi, A.; Dassano, G.; Pirinoli, P. Beam Scanning Capabilities of a 3D-Printed Perforated Dielectric Transmitarray. Electronics 2019, 8, 379. [CrossRef]

5. Salem Hesari, S.; Bornemann, J. Design of a SIW Variable Phase Shifter for Beam Steering Antenna Systems. Electronics 2019, 8, 1013. [CrossRef]

6. Zhu, H.; Chen, W.I.; Huang, J.; Wang, Z.; Yu, F. A High-Efficiency K-band MMIC Linear Amplifier Using Diode Compensation. Electronics 2019, 8, 487. [CrossRef]

7. Doo, J.; Park, W.; Choe, W.; Jeong, J. Design of Broadband W-Band Waveguide Package and Application to Low Noise Amplifier Module. Electronics 2019, 8, 523. [CrossRef]

8. Yang, X.; Liu, X.; Yu, S.; Gan, L.; Zhou, J.; Zeng, Y. Permittivity of Undoped Silicon in the Millimeter Wave Range. Electronics 2019, 8, 886. [CrossRef]

9. Castanheira, D.; Teodoro, S.; Simões, R.; Silva, A.; Gameiro, A. Multi-User Linear Equalizer and Precoder Scheme for Hybrid Sub-Connected Wideband Systems. Electronics 2019, 8, 436. [CrossRef]

10. Aldalbahi, A. Multi-Backup Beams for Instantaneous Link Recovery in mmWave Communications. Electronics 2019, 8, 1145. [CrossRef] 
11. Hriba, E.; Valenti, M.C. Correlated Blocking in mmWave Cellular Networks: Macrodiversity, Outage, and Interference. Electronics 2019, 8, 1187. [CrossRef]

12. Duarte, L.; Gomes, R.; Ribeiro, C.; Caldeirinha, R. A Software-Defined Radio for Future Wireless Communication Systems at $60 \mathrm{GHz}$. Electronics 2019, 8, 1490. [CrossRef]

(C) 2020 by the author. Licensee MDPI, Basel, Switzerland. This article is an open access article distributed under the terms and conditions of the Creative Commons Attribution (CC BY) license (http://creativecommons.org/licenses/by/4.0/). 